\title{
Failure Behavior of Thin Disc Sandstone under Coupled Bending- Seepage Condition
}

\author{
Luzhen Wang ${ }^{1}$ and Hailing Kong $\mathbb{B}^{1,2}$ \\ ${ }^{1}$ College of Civil Engineering, Yancheng Institute of Technology, Yancheng, Jiangsu 224051, China \\ ${ }^{2}$ Institute of Coastal Ultra-Soft Soil, Yancheng Institute of Technology, Yancheng, Jiangsu 224051, China \\ Correspondence should be addressed to Hailing Kong; hailkong@126.com
}

Received 8 April 2020; Revised 22 June 2020; Accepted 8 July 2020; Published 28 August 2020

Academic Editor: Yingchun Li

Copyright (c) 2020 Luzhen Wang and Hailing Kong. This is an open access article distributed under the Creative Commons Attribution License, which permits unrestricted use, distribution, and reproduction in any medium, provided the original work is properly cited.

\begin{abstract}
A floor aquifuge usually bends and fails when mining above a confined aquifer, which may lead to water inrush disaster. The floor aquifuge was simplified as a thin disc model in this paper, and a series of coupled bending-seepage tests of sandstone were carried out by a patent test system. The variation characteristics of load-displacement, load-time, and permeability-time were analyzed. The deflection and stress in the thin disc rock samples were deduced; the initiation and propagation of cracks were analyzed. The failure behavior of the thin disc rock samples was described. It shows the following: (1) The bending failure behavior relates to the stress distribution and crack evolution inside the thin disc. (2) The main cause of crack initiation is a tension-shear failure. (3) The $5 \mathrm{~mm}$ thickness thin discs form petal-shaped cracks, due to tensile stress, while petal-shaped cracks only appear at the cap block of the $10 \mathrm{~mm}$ discs, which are sheared into two pieces along the conical surface with an inclination about $45^{\circ}$. (4) Water inrush occurs after bending failure in the floor aquifuge, and it is an opportune moment to grout along the crack propagation trend lines to prevent the water inrush disasters.
\end{abstract}

\section{Introduction}

Due to the gradual depletion of shallow mineral resources, mining activities are shifted to the deep. In deep mining activities, geological conditions become complex; confined water pressure increased. Continuous deep mining may result in bending deformation and failure of the floor aquifuge, which may link the groundwater to the working face, and induce water inrush accidents [1-4]. Hence, the bending failure of the floor above a confined aquifer is one of the reasons to induce water inrush.

Scholars began to study the mechanism of floor breakage and water inrush since the last century. Some important theories have been proposed successively, such as the key stratum theory, three-underlying belts theory, in situ rifting and zero failure theory, relative aquifuge thickness and water inrush coefficient method, and water inrush critical index method [5-9]. In recent years, due to the complex geological background and mining conditions, the floor breakage and water inrush mechanisms have been extensively and deeply studied based on the above theories, and new achievements emerged endlessly.

A large-scale model test is one of the effective means to reproduce the process of water inrush from floor breakage. Zhao et al. [10, 11] developed a large-scale threedimensional solid-fluid coupling simulation experimental equipment, analyzed the wall rock distortion and breakage process, and described the variation law of stress and water pressure and their influence on water inrush. Li et al. [12] divided the mining-induced floor stresses into three distinct stages with the help of a fluid-solid coupling model test system. Chen et al. [13] described the crack formation and evolution law in the floor aquifuge by the solid-fluid coupling similar simulation test system and found that most mining cracks were vertical tensile cracks, shear cracks, and layer cracks. Kang et al. [14] studied the failure law of the floor after mining using a large-scale simulation test system and divided the floor fracture belt into an open-off-cut fracture zone, central goaf compaction zone, and working-face fracture zone. Liu et al. [15] found that the failure range 
morphological map of the mining floor was approximately a spoon shape and obtained the maximum failure depth of the floor aquifuge by similar simulation tests. Based on the multifunctional simulation test apparatus, Hua et al. [16] pointed out that the floor heave was mainly composed of the compression bending type, shear dislocation type, and extrusion fluidity type, and the floor heave was mainly caused by the tensile failure or tensile-shear failure.

The similar model test can reproduce the process of floor's breakage and water inrush, but it still has some disadvantages; for example, the model sizes are usually too large, cost too much, and last for long test periods. Therefore, theoretical research and numerical calculation are essential.

Miao et al. [17] simplified the floor aquifuge to a rock beam model with both ends fixed and loaded uniformly and analyzed the strength characteristics and waterresisting performance of the floor aquifuge. Sun and Wang [18] regarded the floor aquifuge as a square elastic thin plate with fixed constraints on four sides and deduced an instability mechanics criterion of the inclined floor water-resisting key strata using the elastic thin plate theory. Gao et al. [19] established a fracture mechanics model based on the thin plate theory and regarded that the essence of water inrush in the mining field was the result of the accumulation of microcracks and propagation of macrocracks in the floor aquifuge caused by mining-induced stress and confined water pressure. Wang et al. [20] established a plate model subjected to horizontal extrusion force, deduced the critical load of floor buckling failure based on the thin plate yield theory, and obtained that the floor thickness was the main factor affecting the critical load. Guo et al. [21] analyzed the distribution of displacement and pore water pressure on the floor using Comsol Multiphysics and pointed out that the key cause of water inrush was the release of energy from the floor above the confined water aquifer when mining. Pang [22] simplified the layered floor to homogeneous elastic plates, calculated the floor failure depth by means of the average modulus method, and considered that the lithology and composite structure of the floor are two important factors affecting the failure depth. Xie [23] used Flac3D to analyze the damage law of elastic modulus of the floor aquifuge caused by mining qualitatively and found that the floor crack rate controlled the stress distribution in the floor and the thickness of floor aquifuge played an important role in controlling the displacement and failure depth of the floor. Obviously, the mechanism of water inrush can be clarified by mastering the failure behavior in the floor aquifuge.

The research above studied the stress distribution [10-12, $17,23]$, displacement change [10, 11, 21, 23], crack evolution $[13,14,19,23]$, and failure law $[15,16,18,20,22]$ in the floor aquifuge. The achievements reach a consensus that (1) the essence of water inrush from the floor aquifuge is the result of the combined action of mining-induced stress and confined water pressure, (2) the stress variation and crack evolution in the floor may lead to water inrush, and (3) the thickness and lithology of the floor aquifuge are two important factors affecting the failure behavior of the floor. However, the above studies ignored the correlation between the distribution of stress and the propagation of cracks when the floor aquifuge was bending, and the formation and propagation of cracks have not been described in-depth, so the bending failure characteristics and the induced water inrush behavior in the floor aquifuge need to be studied further.

To this end, this paper established a thin disc model, conducted the bending-seepage tests of different thicknesses and lithology under the coupled bending-seepage condition, calculated the deflection and stresses inside the thin disc gray sandstone and red sandstone, revealed the formation and propagation mechanism of the cracks in the thin disc rock with different thicknesses and lithology, and described the bending failure behavior in the floor aquifuge, as well as the bending-failure-induced water inrush behavior. This research is expected to provide references for the description of floor failure and the prevention of water inrush.

\section{Simplified Model and Experimental Process}

2.1. Simplified Model. With coal extraction continuing, the confined water pressure and the mining-induced stress become the force sources. Subject to their joint action, the floor aquifuge undergoes bending deformation. In the bending floor aquifuge, the cracks are formed, developed, and penetrated, and water flow changes from seepage to turbulence and rushes into the working face, which may cause water inrush disaster.

A simplified model is shown in Figure 1, established based on the following assumptions:

(1) The floor aquifuge in practical engineering is assumed as a circular thin plate relative to the stratum; the selfweight of the thin disc rock sample is ignored.

(2) Owing to the strength and stiffness of the surrounding rock mass that are far greater than those of the floor aquifuge, the constraint of the thin disc rock sample is peripheral clamping.

(3) The floor aquifuge is assumed above the confined aquifer. The confined water pressure is regarded as a uniformly distributed pore pressure, $q$, distributed on the lower surface of the thin disc rock sample.

(4) Excavation disturbances induce floor heave; the upward bending deformation is applied to the thin disc rock sample, which is realized by applying an upward concentrated force, $P$, on the lower surface of the thin disc rock sample by a conical indenter.

As shown in Figure 1(c), the peripheral clamping is equivalent to a force couple, $M$, and a force, $F / 2 \pi a$. $a$ is the radius of the thin disc rock sample, $F$ is a circumferential load applied by the Material Testing Machine, and a retaining ring is used to act on the annular upper surface of the thin disc rock sample.

2.2. Testing System. In order to simulate the heave and breakage of the floor aquifuge and realize the coupled bending deformation and water flow applied on the floor aquifuge, a testing system that can conduct the coupling bendingseepage test is designed and manufactured $[3,24]$. It consists of an axial loading subsystem, a pore pressure loading and 


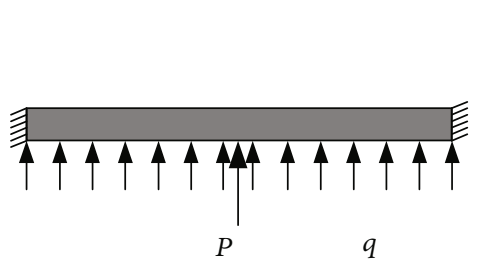

(a)

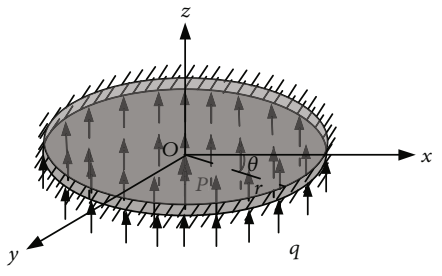

(b)

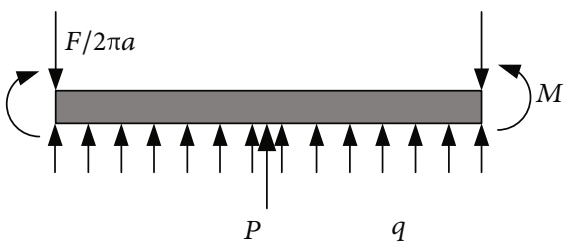

(c)

FIgURE 1: Simplified model for floor aquifuge.

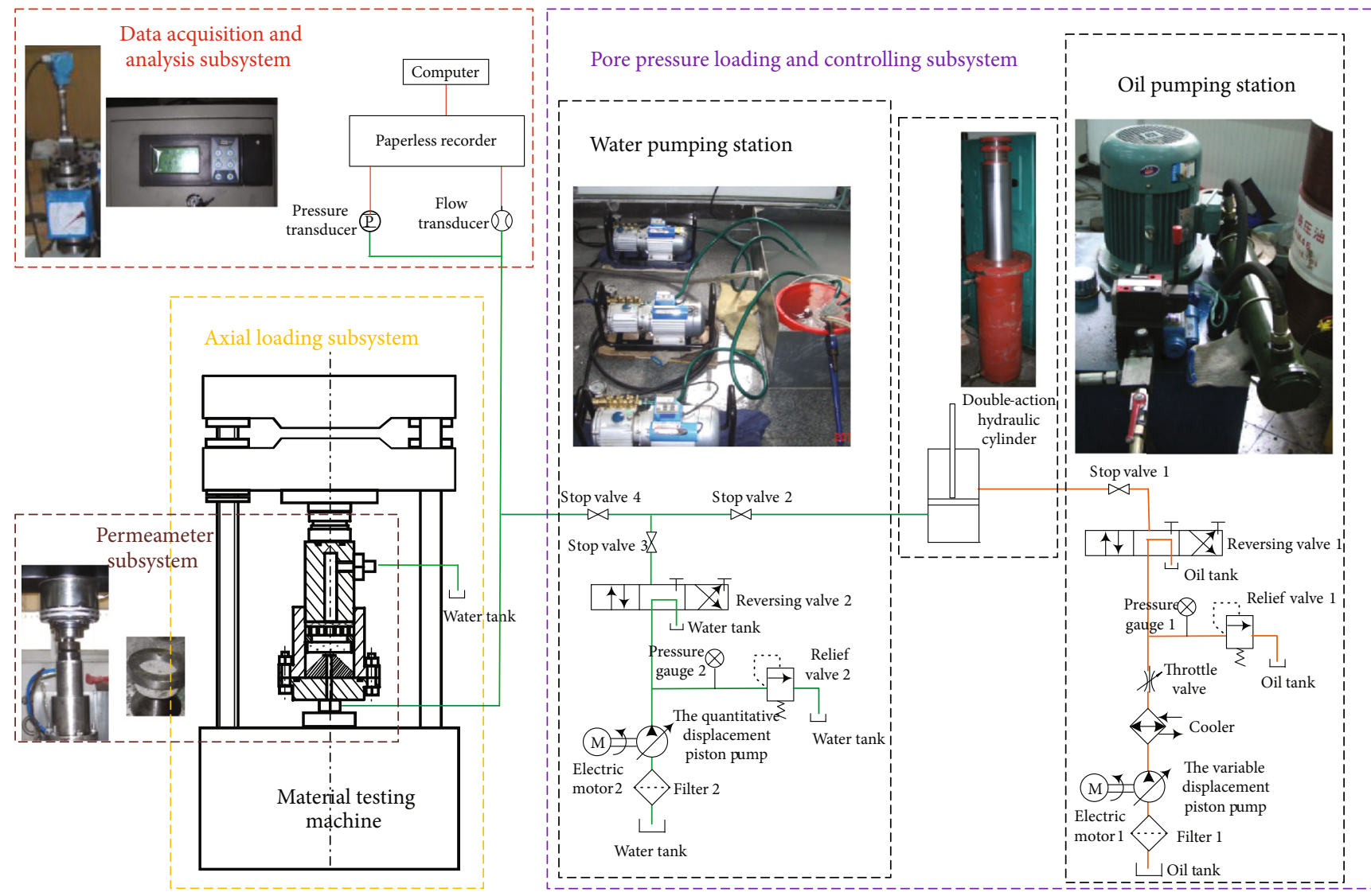

Figure 2: Testing system.

controlling subsystem, a permeameter subsystem, and a data acquisition and analysis subsystem. The overall design of the testing system is shown in Figure 2.

As the core of the testing system, the permeameter subsystem contains a bottom plate, a cylinder, a permeable piston, a conical indenter, a retaining ring, seals, etc., shown in Figure 3. The thin disc rock sample is fixed between the retaining ring and the conical indenter. It is critical to tightly seal the interspace between the outer boundary of the sample and the cylinder wall using high water materials and to ensure that the liquid only flows within the rock sample but not seeps out from surrounding voids before and during the loading process.

The test adopted the steady-state permeation method. Stable pore water pressure was provided by driving oil pressure in the pore pressure loading and controlling subsystem. Water flowed through the pressure transducer, flow trans- ducer, and the inlet at the bottom plate, entered the conical indenter, and evenly distributed on the lower surface of the thin disc rock sample to simulate the action of the confined water pressure on the floor aquifuge. An axial load was applied onto the piston of the permeameter, then loaded on the upper surface of the thin disc rock sample through the retaining ring as circumferential load. Under the bidirectional actions of concentrated force from the conical indenter and circumferential load from the retaining ring, the rock sample underwent bending deformation, which was used to simulate the floor heave bending deformation of the floor aquifuge due to excavation disturbances.

\subsection{Testing Scheme}

2.3.1. Material Characterization and Sample Preparation. The floor aquifuge in Pan mine in Sichuan is taken as the 


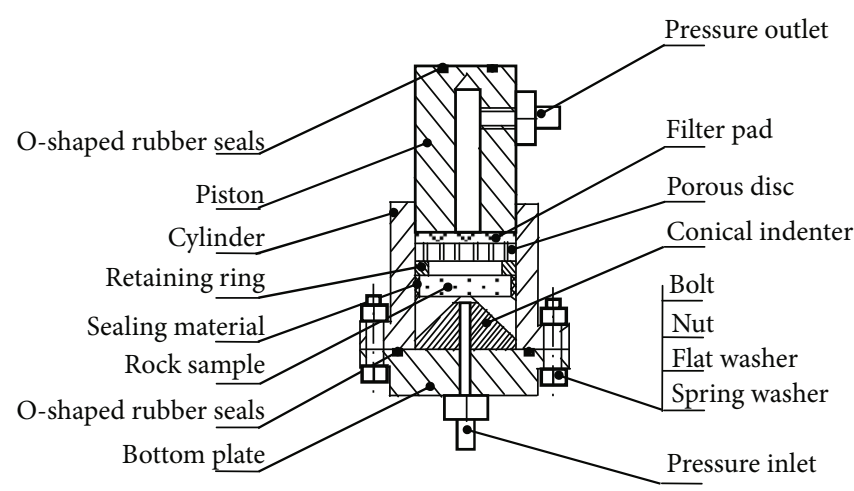

Figure 3: Schematic of the permeameter.

example in this paper, which is mainly gray sandstone and red sandstone. All samples were acquired from a single rock block to ensure their similar physical properties, respectively. The physical and mechanical properties are listed in Table 1.

Based on the simplified model of the floor aquifuge and the diameter of the permeameter cylinder, the rock sample was processed as a $50 \mathrm{~mm}$ diameter disc. According to the definition of the thin plate theory, the thickness-diameter ratio should be less than $1 / 5$. Therefore, two thicknesses, $5 \mathrm{~mm}$ and $10 \mathrm{~mm}$, are selected in this research.

Samples were examined before testing to exclude those with obvious macroscopic defects and to ensure the testing values free from the impacts of macrojoints and fissures. The structures of the selected thin disc rock samples were compact, and there was no visible natural microfissure. Then, thin disc rock samples were polished to keep the surface smooth at two ends.

Taking lithology and thickness as the influencing factors, four independent tests were carried out, marked GS05, GS10, RS05, and RS10. Three samples were tested in each independent test.

2.3.2. Testing Design. At the beginning of testing, water was injected into the permeameter to saturation at least half an hour. Then, the pore pressure was loaded, and the sealing performance of the system was timely checked. According to relevant geological data, the pore pressure was set as $2 \mathrm{MPa}$ in this test. When the pore pressure was completely stable at $2 \mathrm{MPa}$, the rock sample was loaded by the axial loading subsystem in the displacement control mode at a loading rate of $0.5 \mathrm{~mm} / \mathrm{min}$ till the rock sample failed.

In addition, the pore pressure $q$ and water flow $Q$ were simultaneously acquired from the beginning of loading; the load $F$ and displacement $u$ during bending deformation were real-time recorded.

Permeability, $k$, can be calculated by Darcy's law as below:

$$
k=\frac{\mu v}{q / \delta},
$$

where $\mu$ is the dynamic viscosity of water, $v$ is the seepage speed calculated from $v=Q / \pi a^{2}, q$ is the pore pressure, and $\delta$ is the thickness of the thin disc rock sample.

\section{Experimental Results}

3.1. Variation Characteristics of Load-Displacement Curves. Figure 4 shows the load-displacement $(F-u)$ curves of the gray sandstone and red sandstone with two different thicknesses. They have similar variation characteristics, which can be divided into four stages $O A-A B-B C-C D E$, as shown in Figure 5.

The section of the $O A$ segment is shorter and steeper. This section contains adaptive adjustment and elastic deformation of the thin disc structure under uniform water pressure and bending load. Obviously, the thin disc samples have low elastic deformation.

The $A B$ segment is a line with a very small slope; the deformation increases significantly while the load-carrying capacity increases very small in this stage. The structure produces large plastic deformation, and microcracks in the disc germinate and develop; floor heave occurs in the $A B$ section $[16,25,26]$.

The $B C$ section has a great slope. With the increase of deformation, the load increases sharply, and the bearing capacity of the thin disc structure is strengthened. In this stage, the crack propagation inside the thin disc changes qualitatively, microcracks develop and grow continuously, forming macrocracks, and the internal structure of the thin disc is damaged gradually. Although the thin disc structure is still in the overall state, the internal cracks penetrate rapidly. The bearing capacity of the thin disc structure reaches its peak value at point $C$, which is listed in Table 2. It presents that the thicker disc rock sample has a greater peak load, the peak value of red sandstone with the same thickness is larger than that of gray sandstone, and the displacement of gray sandstone is less than that of red sandstone.

After the peak value, $C D E$ is the postfracture stage. In this stage, cracks intersect each other, under the action of splitting expansion of pore water pressure, the macrofracture surface is united and formed, and rock blocks slide along the fracture surface, which may cause water inrush $[27,28]$. The bearing capacity of the sample decreases slowly with the increase of deformation in $C D$ and then drops rapidly in $D E$, and the thin disc structure collapses till its bearing capacity loses completely. Generally, if the deformation and heave behavior of the floor have not been dealt with in time before the peak value in the project, it can be remedied in the $C D$ section. 
TABLE 1: Physical and mechanical properties of gray sandstone and red sandstone.

\begin{tabular}{lcc}
\hline Lithology & $\begin{array}{c}\text { Gray } \\
\text { sandstone }\end{array}$ & $\begin{array}{c}\text { Red } \\
\text { sandstone }\end{array}$ \\
\hline Uniaxial compressive strength $\left(\sigma_{c}, \mathrm{MPa}\right)$ & 54.7 & 51.2 \\
Tensile strength $\left(\sigma_{\mathrm{t}}, \mathrm{MPa}\right)$ & 5.02 & 4.71 \\
Elastic modulus $(E, \mathrm{GPa})$ & 32.0 & 29.2 \\
Poisson ratio $(v)$ & 0.23 & 0.16 \\
Density $\left(\rho, \mathrm{kgm}^{-3}\right)$ & 2473 & 2574 \\
Internal friction angle $\left(\phi,{ }^{\circ}\right)$ & 47.8 & 43.0 \\
Cohesion $(C, \mathrm{MPa})$ & 21.2 & 22.9 \\
\hline
\end{tabular}

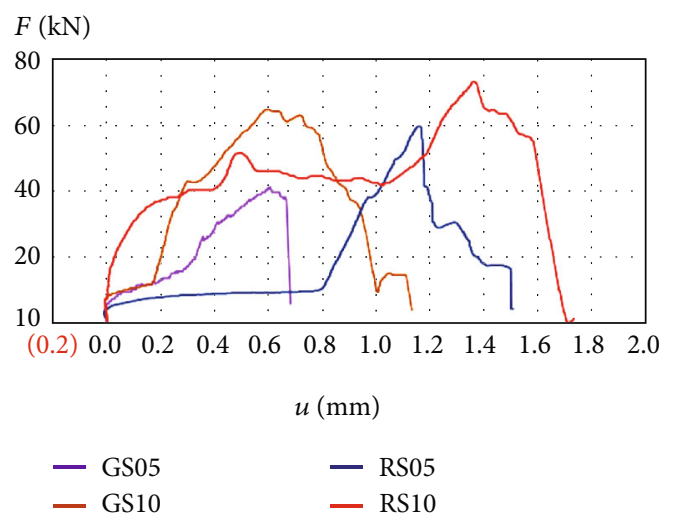

Figure 4: Load-displacement curves of four different sandstone samples.

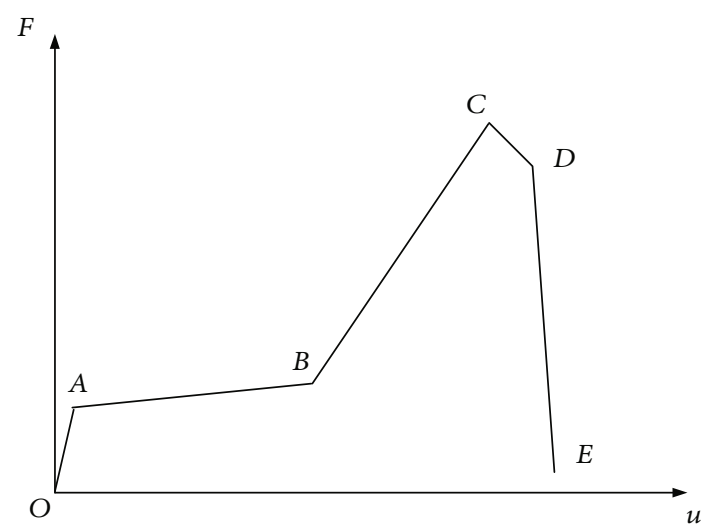

FIGURE 5: Four-stage dividing sketch of load-displacement curves.

Because the floor still has its bearing capacity, it is not too late to control the floor deformation and heave behavior by means of grouting. Mastering the characteristics of crack initiation and propagation can better guide grouting.

3.2. Time-Varying Characteristics of Load and Permeability. Figure 6 shows the load-time $(F-t)$ curves and permeabilitytime $(k-t)$ curves of the gray sandstone and red sandstone with two different thicknesses.

The permeability of the intact thin disc rock sample is about $10^{-17} \mathrm{~m}^{2}$ at the beginning of the experiments, which
TABLE 2: The peak values for different samples.

\begin{tabular}{lllll}
\hline Sample number & GS05 & GS10 & RS05 & RS10 \\
\hline Peak load (kN) & 4.065 & 6.419 & 5.915 & 7.283 \\
Displacement on the peak load (mm) & 0.609 & 0.603 & 1.162 & 1.363 \\
\hline
\end{tabular}

is consistent with the testing result of standard intact rock samples [29-37]. It increases rapidly after bending failure occurred several seconds, water flow changes from seepage to turbulence simultaneously, and then, water inrush may occur. In this process, permeability evolved from $10^{-17} \mathrm{~m}^{2}$ up to $10^{-11} \mathrm{~m}^{2}$, increasing six orders of magnitude. Its evolution rule is obviously different from standard rock samples [32], in which permeability usually increases three to four orders of magnitude after the postpeak strength. Obviously, the permeability of the thin disc structure changes greatly with stronger mutation, because the stress distribution and crack evolution of the thin disc are different from that of the standard rock sample.

As shown in Figure 6, the peak permeability always lags the peak load, indicating that it still has time and opportunity to take measures to prevent water inrush disaster, which is consistent with the $C D$ section in Figure 5. Table 3 lists the occurrence time of peak load and peak permeability, as well as the lagging time.

The sample GS05 experienced the longest time; this is because the sealing material between the outer boundary of the sample and the cylinder wall was compacted for a long time. The compression of the sealing material only prolongs the test time but does not affect the deformation measurement of the sample. Because of the difference in experimental operation, the peak load and permeability occurrence times of four samples cannot be compared separately. Only the lagging time can be analyzed; it shows that the lagging time of gray sandstone is longer than that of red sandstone. It is because the brittle behaviors of the thin disc in the postfracture stage are different, which relates to the crack propagation. The longer the lagging time is, the longer the time that can be used for water inrush prevention and control is, the more effective the water inrush risk can be reduced.

3.3. Bending Failure Pattern. Figure 7 shows the bending failure patterns of the four thin disc rock samples. The $5 \mathrm{~mm}$ thickness disc rock samples formed petal-shaped cracks after bending failure, as shown in Figures 7 (a) and 7(c). For the $10 \mathrm{~mm}$ thickness disc samples, a cap block was cut out along a conical surface with an inclination about $45^{\circ}$, as shown in Figures 7(b) and 7(d), and petal-shaped cracks also appear in the cap block.

Obviously, when the thin disc rock samples are under the coupled bending-seepage condition, their failure behaviors belong to the problem of structural failure. It is related not only to material properties but also to the structural properties and external force characteristics. In order to analyze the bending failure behavior in-depth, the stress distribution and crack evolution in the thin disc rock structures should be studied further. 


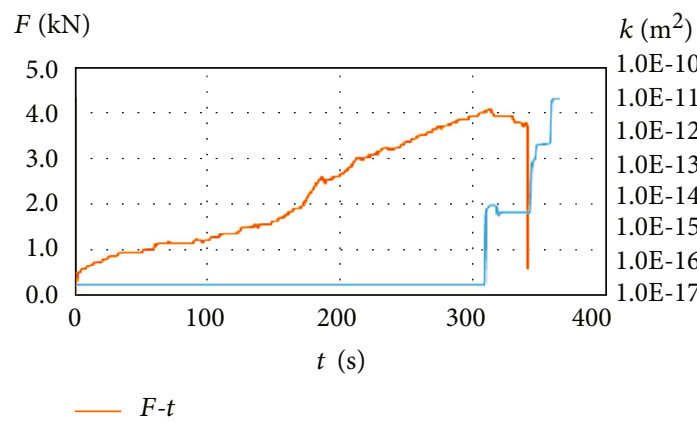

(a) GS05

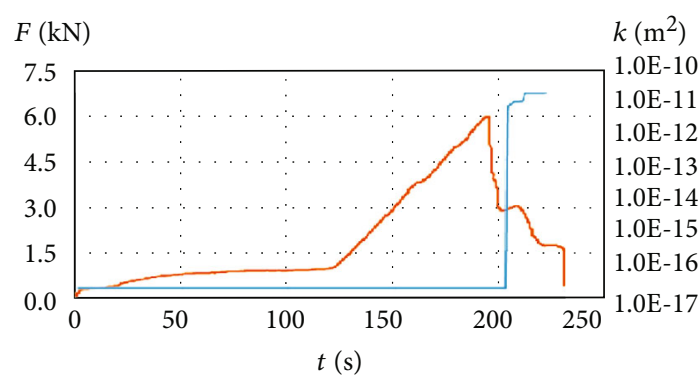

- F-t

$k-t$

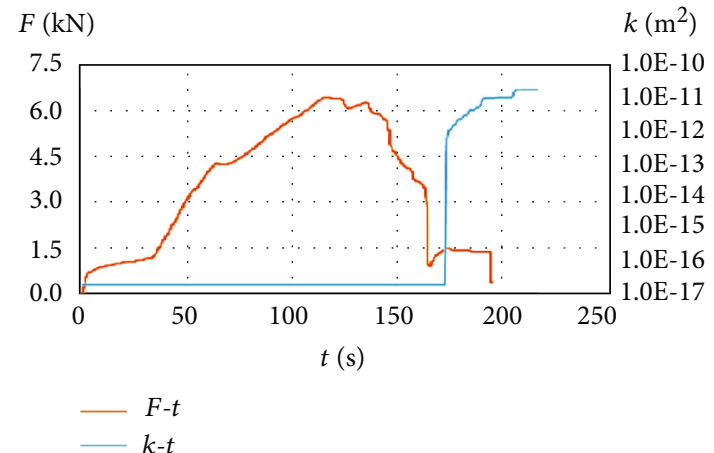

(b) GS10

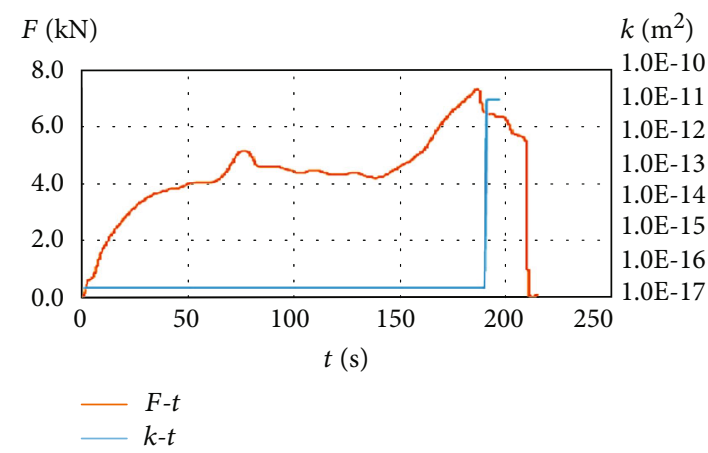

(d) RS10

(c) RS05

FIGURE 6: Time-varying characteristics of load and permeability.

TABle 3: The lagging times for different samples.

\begin{tabular}{|c|c|c|c|c|}
\hline Sample number & GS05 & GS10 & RS05 & RS10 \\
\hline Time on the peak load occurrence (s) & 310 & 118 & 193 & 186 \\
\hline Time on the peak permeability occurrence (s) & 356 & 174 & 203 & 190 \\
\hline Lagging time (s) & 46 & 56 & 10 & 4 \\
\hline
\end{tabular}

\section{Discussion}

The hard rock floor aquifuge is mainly a local plastic failure, and the stability coefficient is generally high; it can be solved with the elastic solution [38].

\subsection{Deflection Calculation and Distribution in Thin Disc Rock} Samples. Based on the simplified model in Figure 1(c), circumferential load, $F$, and pore pressure, $q$, can be measured timely during the test; the concentrated force, $P$, and the force couple, $M$, can be calculated as

$$
\begin{aligned}
P & =F-q \pi a^{2}, \\
M & =\frac{a}{2}\left(\frac{F}{2 \pi}-q a\right) .
\end{aligned}
$$

In polar coordinates, as shown in Figure 1, the transverse loads on the thin disc rock sample are symmetrical around the $z$-axis, which is a vertical plate face up. The deflection, $w$, of the elastic thin disc is also symmetrical around the $z$ -axis, and it is a function of $r$ but does not change with $\theta$. When the thin disc rock sample bends axial-symmetrically, the differential equation of the deflection is

$$
\left(\frac{\mathrm{d}^{2}}{\mathrm{~d} r^{2}}+\frac{1}{r} \frac{\mathrm{d}}{\mathrm{d} r}\right)\left(\frac{\mathrm{d}^{2} w}{\mathrm{~d} r^{2}}+\frac{1}{r} \frac{\mathrm{d} w}{\mathrm{~d} r}\right)=\frac{q}{D},
$$

where $D=E \delta^{3} / 12\left(1-v^{2}\right)$ is the bending stiffness of thin disc and $E$ and $v$ are elastic modulus and Poisson's ratio, respectively.

A semi-inverse method is used to solve the differential Equation (3); the general solution for the deflection of the thin disc rock sample is

$$
w=\frac{q}{64 D} r^{4}+A_{1} r^{2}+A_{2} r^{2} \ln \frac{r}{a}+A_{3} \ln \frac{r}{a}+A_{4},
$$

where $A_{1}, A_{2}, A_{3}$, and $A_{4}$ are coefficients, determined by the boundary conditions. 


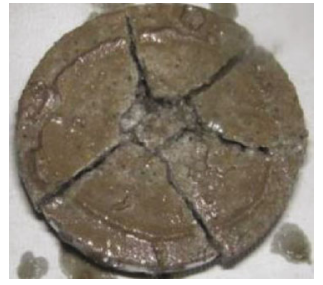

(a) GS05

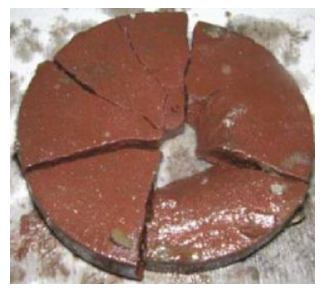

(c) RS05

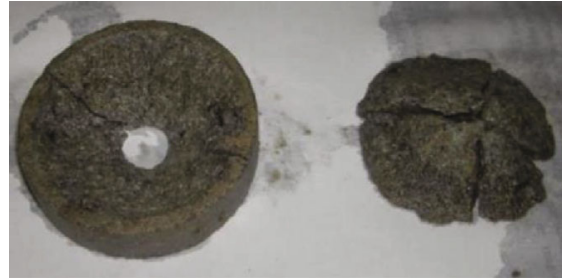

(b) GS10

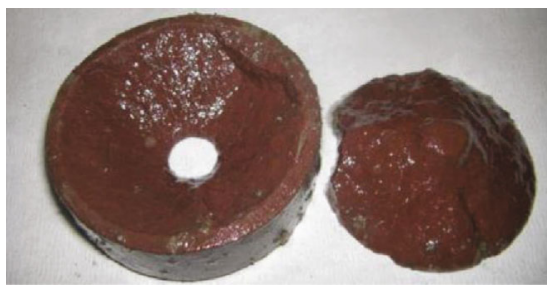

(d) RS10

FIgURE 7: Bending failure patterns.

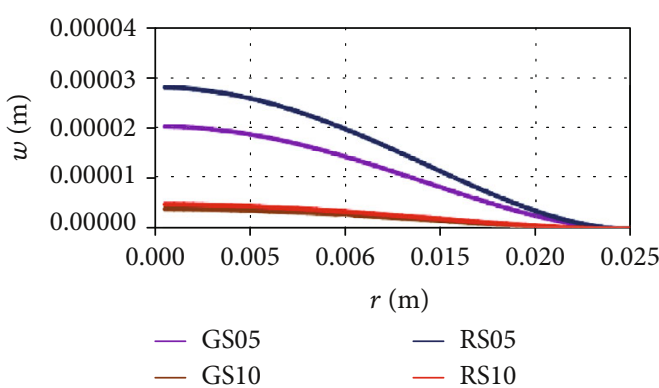

(a) When $P=0$

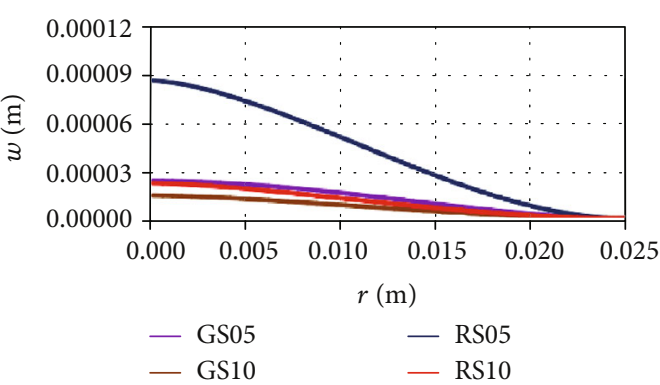

(b) When $P=P_{\max }$

Figure 8: Deflection distribution curves.

Based on the boundary conditions in the mechanical model, the deflection is expressed as

$$
w=\frac{q}{64 D}\left(a^{2}-r^{2}\right)^{2}+\frac{P}{8 \pi D}\left[\frac{1}{2}\left(a^{2}-r^{2}\right)+r^{2} \ln \frac{r}{a}\right]
$$

Applying Equation (5), the deflection distribution inside the thin disc rock sample along the radius direction at different loading times could be obtained.

The deflection distributions along the radius direction when $P=0$ are shown in Figure 8(a). It shows that when the thin disc rock sample is only under the action of pore pressure, the maximum deflections of samples GS05, GS10, RS05, and RS10 are $0.0191,0.00374,0.0264$, and $0.0046 \mathrm{~mm}$, respectively. It can be inferred that the thinner the floor aquifuge, the larger the deformation caused by the confined water pressure.

Figure 8 (b) shows the deflection distributions at the time of peak load appearance, $P=P_{\max }$, the maximum deflections of samples GS05, GS10, RS05, and RS10 are 0.0218, 0.0132, 0.0797 , and $0.0203 \mathrm{~mm}$, respectively. Mining disturbance induces further bending deformation of the floor. Under the combined action of mining-induced stress and confined

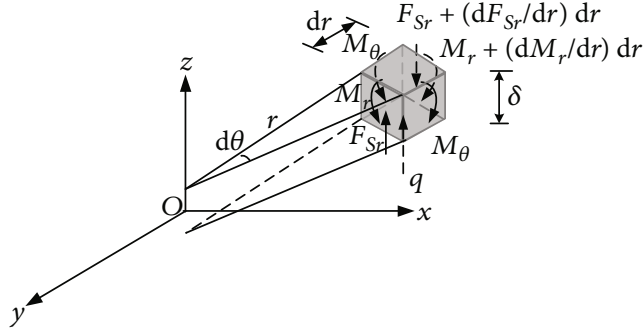

FIgURE 9: Internal force distribution of microelement in the thin disc rock sample.

water pressure, the deflection of the floor aquifuge is 1.2 to 4 times of that under the alone confined water pressure.

It is worth noting that these deflections are the elastic ultimate load-bearing displacements. The displacements are different from the values in Table 2 , which includes not only the deformation of the thin disc rock sample but also the deformation of the sealing material and the displacement of the sample after being fractured.

The maximum deflections both occur at the center of the thin disc rock sample when $P=0$ and $P=P_{\max }$; as a result, the center of the disc is the dangerous position that the disc may break from here. 
Sandstone is a typical brittle material at room temperature; its elastic deformation is weak. The bending failure of the thin disc rock sample mainly results from the strength, but not the stiffness. Therefore, in addition to analyzing the deformation in the disc, stress distribution should be emphasized.
4.2. Stress Calculation and Distribution in Thin Disc Rock Samples. As Figure 9 shows, through the analysis of the microelement in the thin disc rock sample, the internal force equation of the element is calculated as follows:

$$
\left\{\begin{array}{l}
M_{r}=-D\left(\frac{\mathrm{d}^{2} w}{\mathrm{~d} r^{2}}+\frac{v}{r} \frac{\mathrm{d} w}{\mathrm{~d} r}\right)=-\frac{P}{4 \pi}\left(1+\ln \frac{r}{a}+v \ln \frac{r}{a}\right)+\frac{q}{16}\left[(1+v)\left(a^{2}-r^{2}\right)-2 r^{2}\right], \\
M_{\theta}=-D\left(\frac{1 \mathrm{~d} w}{r} \frac{\mathrm{d}^{2} w}{\mathrm{~d} r}+v \frac{P}{\mathrm{~d} r^{2}}\right)=-\frac{P}{4 \pi}\left(v+\ln \frac{r}{a}+v \ln \frac{r}{a}\right)+\frac{q}{16}\left[v\left(a^{2}-3 r^{2}\right)+\left(a^{2}-r^{2}\right)\right], \\
M_{r \theta}=0 \\
F_{S r}=-D\left(\frac{\mathrm{d}^{3} w}{\mathrm{~d} r^{3}}+\frac{1}{r} \frac{\mathrm{d}^{2} w}{\mathrm{~d} r^{2}}\right)=-\frac{P}{4 \pi r}\left(2+\ln \frac{r}{a}\right)+\frac{q}{16 r}\left(a^{2}-9 r^{2}\right), \\
F_{S \theta}=0 .
\end{array}\right.
$$

Using Equation (6), the distribution of internal forces along the radius direction can be solved and drawn, as shown in Figure 10.

As seen in Figure 10(a), the reverse bending point of $M_{r}$ is about $0.01 \mathrm{~m}$ away from the center of the disc. When $r<$ $0.01 \mathrm{~m}$, the upper surface of the disc is in tension and the lower surface is in compression, and when $r>0.01 \mathrm{~m}$, it is just the opposite. All the samples except for GS05 have the maximum value of $M_{r}$ at the center, where it is the most dangerous cross-section. Particularly, the maximum value of $M_{r}$ occurs at the edge in the sample of GS05. The value in the center is slightly less than that in the edge; both the center and edge cross-sections are dangerous sections.

It can be seen from Figure 10(b) that the $M_{\theta}$ distribution curves are similar to the distribution curves of $M_{r}$, but the reverse bending point is different, which is about $0.022 \mathrm{~m}$ away from the center. When $r<0.022 \mathrm{~m}$, the upper surface of the disc rock sample is in tension and the lower surface is in compression, and when $r>0.022 \mathrm{~m}$, the upper surface is compressed and the lower surface is tensed. The maximum value of $M_{\theta}$ occurs at the center, so the central cross-section is the most dangerous point.

It can be seen from Figure 10(c) that when $r \approx 0.004 \mathrm{~m}$, the shear force $F_{S r}$ in the disc changes from positive to negative. The maximum value of $F_{S r}$ occurs at the center of the disc, so it is the most dangerous cross-section; the direction of the shear force at the dangerous section is downward.

From Equations (5) and (6), the stress at every crosssection of the thin disc rock sample can be calculated as follows:

$$
\left\{\begin{array}{l}
\sigma_{r}=-\frac{E z}{1-v^{2}}\left(\frac{\mathrm{d}^{2} w}{\mathrm{~d} r^{2}}+\frac{v \mathrm{~d} w}{r} \frac{\mathrm{d} r}{\delta^{3}}\right)=\frac{12 M_{r}}{\delta^{3}} z=-\frac{3}{\delta^{3}}\left\{\frac{P}{\pi}\left(1+\ln \frac{r}{a}+v \ln \frac{r}{a}\right)-\frac{q}{4}\left[(1+v)\left(a^{2}-r^{2}\right)-2 r^{2}\right]\right\} z \\
\sigma_{\theta}=-\frac{E z}{1-v^{2}}\left(\frac{1}{r} \frac{\mathrm{d} w}{\mathrm{~d} r}+v \frac{\mathrm{d}^{2} w}{\mathrm{~d} r^{2}}\right)=\frac{12 M_{\theta}}{\delta^{3}} z=-\frac{3}{\delta^{3}}\left\{\frac{P}{\pi}\left(v+\ln \frac{r}{a}+v \ln \frac{r}{a}\right)-\frac{q}{4}\left[v\left(a^{2}-3 r^{2}\right)+\left(a^{2}-r^{2}\right)\right]\right\} z \\
\tau_{r \theta}=\tau_{\theta r}=0 \\
\tau_{r z}=\frac{6 F_{S r}}{\delta^{3}}\left(\frac{\delta^{2}}{4}-z^{2}\right)=-\frac{3}{\delta^{3}}\left[\frac{P}{2 \pi r}\left(2+\ln \frac{r}{a}\right)-\frac{q}{8 r}\left(a^{2}-9 r^{2}\right)\right]\left(\frac{\delta^{2}}{4}-z^{2}\right) \\
\tau_{\theta z}=\tau_{z \theta}=0 .
\end{array}\right.
$$

Using Equation (7), the stress distribution at the central dangerous cross-section along the direction of the disc thickness (i.e., the $z$-axis direction) is shown in Figure 11(a). For the sample of GS05, the edge cross-section is dangerous too; its stress distribution along the direction of the disc thickness is shown in Figure 11(b).

As seen in Figure 11, both $\sigma_{r}$ and $\sigma_{\theta}$ are linearly distributed along the thickness direction, forming the bending 


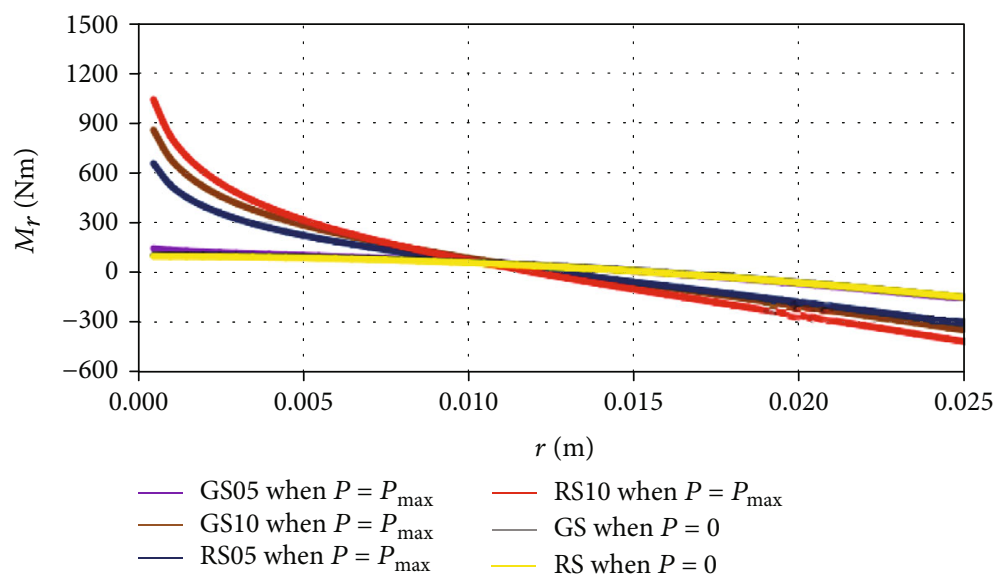

(a) $M_{r}$ distribution curves

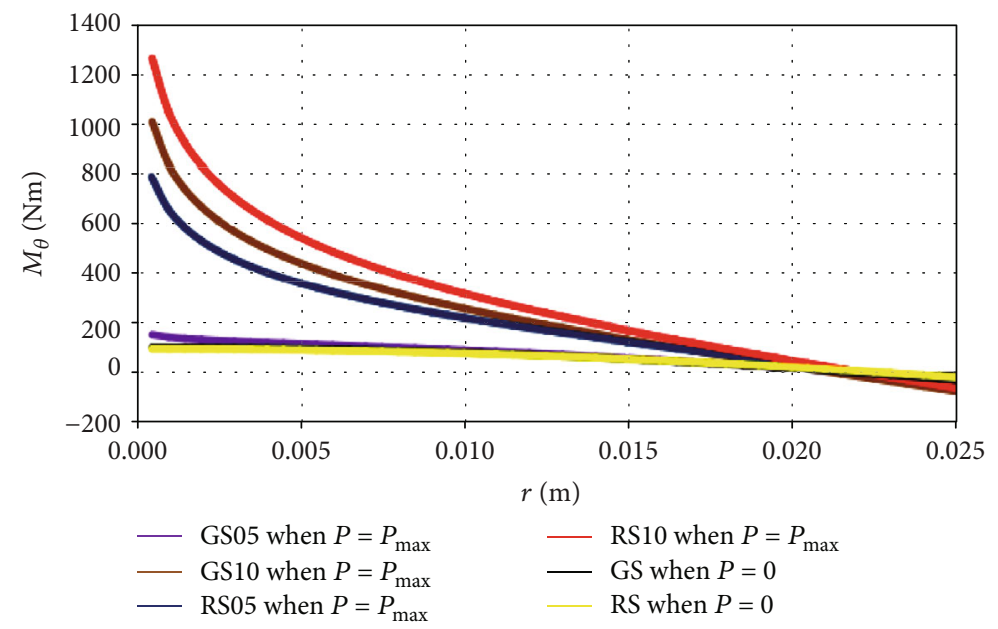

(b) $M_{\theta}$ distribution curves

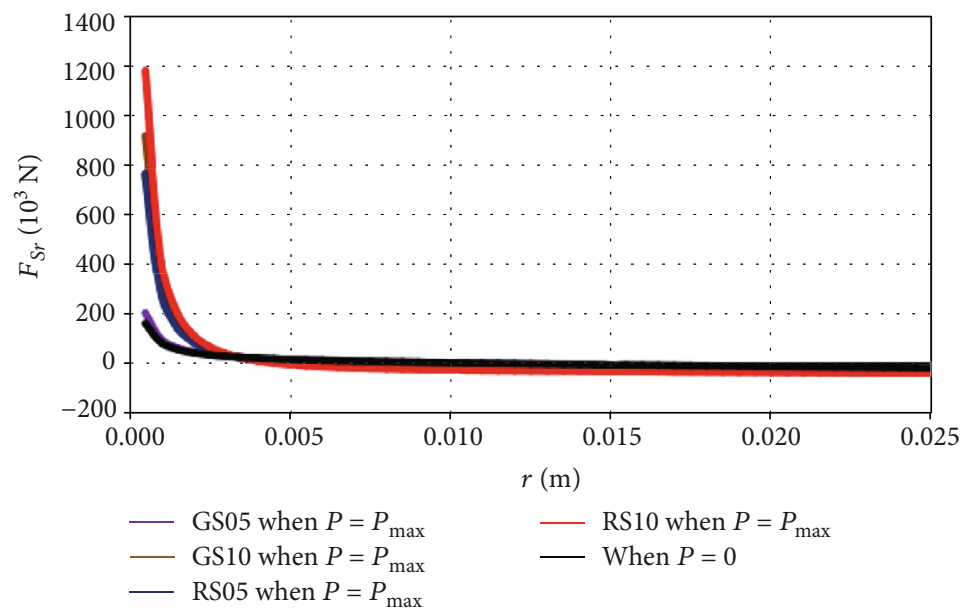

(c) $F_{S r}$ distribution curves

Figure 10: Internal force distribution curves.

moments $M_{r}$ and $M_{\theta}$, respectively. The maximum values of $\sigma_{r}$ and $\sigma_{\theta}$ occur at the upper and lower points of the dangerous cross-sections. $\tau_{r z}$ is parabolically distributed along the thickness direction, constituting the shear force $F_{S r}$. The maximum value $\tau_{r z}$ occurs at the neutral point of the dangerous cross-section.
Summing up, the location and stresses of the dangerous points in the thin disc rock samples can be calculated and are shown in Table 4.

As illustrated in Table 4, for sample GS05, $\sigma_{r \text { max }}$ at the upper and lower points of the edge cross-section is very large, and the thin disc rock sample may be damaged from the 

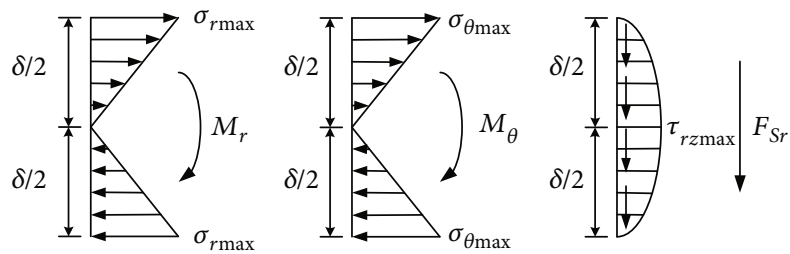

(a) Stress distribution at the central dangerous cross-section along the thickness direction

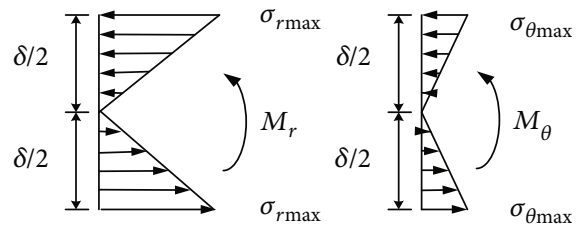

(b) Stress distribution at the edge dangerous cross-section along the thickness direction for the sample of GS05

FIgURE 11: Stress distribution at the dangerous cross-section.

TABLE 4: The location and stresses of the dangerous points in the thin disc rock samples.

\begin{tabular}{|c|c|}
\hline Samples & Location/stresses \\
\hline \multirow{4}{*}{ GS05 } & The upper and lower points of the central cross-section $/ \sigma_{r \max }=22.3 \mathrm{MPa}$ \\
\hline & The upper and lower points of the edge cross-section $/ \sigma_{r \max }=27.0 \mathrm{MPa}$ \\
\hline & The upper and lower points of the central cross-section $/ \sigma_{\theta \max }=23.7 \mathrm{MPa}$ \\
\hline & The neutral point of the central cross-section $/ \tau_{r z \max }=48.8 \mathrm{MPa}$ \\
\hline \multirow{3}{*}{ GS10 } & The upper and lower points of the central cross-section $/ \sigma_{r \max }=46.4 \mathrm{MPa}$ \\
\hline & The upper and lower points of the central cross-section $/ \sigma_{\theta \max }=54.7 \mathrm{MPa}$ \\
\hline & The neutral point of the central cross-section $/ \tau_{r z \max }=130.5 \mathrm{MPa}$ \\
\hline \multirow{3}{*}{ RS05 } & The upper and lower points of the central cross-section $/ \sigma_{r \max }=120.2 \mathrm{MPa}$ \\
\hline & The upper and lower points of the central cross-section $/ \sigma_{\theta \max }=144.8 \mathrm{MPa}$ \\
\hline & The neutral point of the central cross-section $/ \tau_{r z \max }=199.9 \mathrm{MPa}$ \\
\hline \multirow{3}{*}{ RS10 } & The upper and lower points of the central cross-section $/ \sigma_{r \max }=59.8 \mathrm{MPa}$ \\
\hline & The upper and lower points of the central cross-section $/ \sigma_{\theta \max }=72.7 \mathrm{MPa}$ \\
\hline & The neutral point of the central cross-section $/ \tau_{r z \max }=173.3 \mathrm{MPa}$ \\
\hline
\end{tabular}

edge. For samples GS05, GS10, RS05, and RS10, both $\sigma_{r \max }$ and $\sigma_{\theta \max }$ occur at the upper and lower points of the central cross-section, and $\tau_{r z \max }$ occurs at the neutral point of the central cross-section. $\sigma_{\theta \text { max }}$ is larger than $\sigma_{r \text { max }}$ at the upper and lower points of the central cross-section, and the thin disc rock sample may be damaged mainly by $\sigma_{\theta \max }$ from the center.

It also shows that the sample RS05 has the largest $\sigma_{r \text { max }}$, $\sigma_{\theta \text { max }}$, and $\tau_{r z \text { max }}$, followed by RS10, GS10, and GS05. The thin disc red sandstone has higher stress than the gray one. The greater the stress is, the faster the cracks develop in the thin disc, and the shorter the time of water inrush passage through. This is consistent with the experimental phenomenon that the lagging time of red sandstone is shorter than that of gray sandstone in Table 3.

The stress state of dangerous points in the thin disc rock samples can be described as shown in Figure 12.
Figure 13 and Table 5 show the specific locations of the dangerous points on the thin discs and the corresponding stress states.

Based on the description for the location and stress state of the dangerous points on the thin discs, these dangerous points are in the biaxial tensile/compressive stress state, the uniaxial tensile/compressive stress state, and the pure shear stress state, respectively. The structural failure of the thin disc rock sample is mainly due to the stress reaching or exceeding its strength limit, and therefore, the strength condition should be established to reveal the failure mechanism.

4.3. Crack Initiation and Propagation in Thin Disc Rock Samples. Sandstone is a kind of brittle material so that we use the Maximum Tensile Stress Theory and MohrCoulomb Strength Theory to analyze the bending failure behavior. 


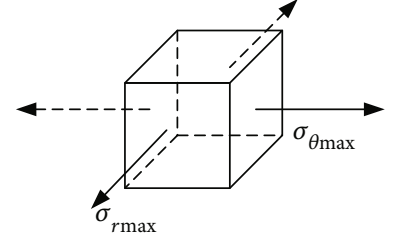

(a) The biaxial tensile stress state

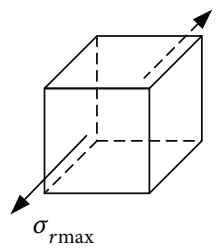

(c) The uniaxial tensile stress state

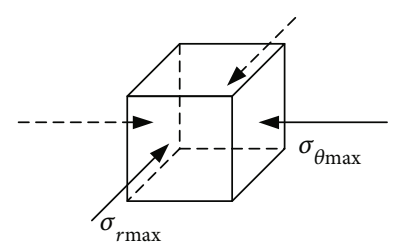

(b) The biaxial compressive stress state

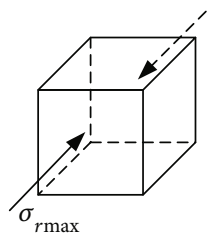

(d) The uniaxial compressive stress state

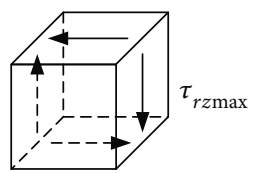

(e) The pure shear stress state

FIGURE 12: Stress state of dangerous points.

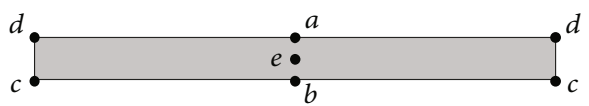

Figure 13: The location of the danger points on thin discs.

4.3.1. The Cause of the Crack Initiation. Combining Figures 12 and 13, the upper points of the central crosssection in the four samples are the dangerous points. They are in the biaxial tensile stress state, and the principal stresses of the dangerous points are $\sigma_{\theta \text { max }}, \sigma_{r \text { max }}$, and 0 . According to the Maximum Tensile Stress Theory, when bending failure occurs, the maximum tangential tensile stress reaches and exceeds the allowable tensile stress. So, the upper points of the central cross-section in the disc, i.e., the points $a$ in Figure 13, are the points of crack initiation, and the disc rock sample is tensed at these points along the tangential direction.

Meanwhile, the lower points of the edge cross-section in sample GS05 are also the dangerous points. They are in the uniaxial tensile stress state, and the principal stresses of the dangerous points are $\sigma_{r \max }, 0$, and 0 . When bending failure occurs in sample GS05, the maximum radial tensile stress reaches and exceeds the allowable tensile stress. Therefore, for the sample GS05, besides the upper points of the central cross-section, the lower points of the edge cross-section, i.e., the points $c$ in Figure 13, are the points of crack initiation, too. That is to say, the sample GS05 is tensed simultaneously at the location $a$ along the tangential direction and at location $c$ along the radial direction.

In addition, the neutral points of the central cross-section in the four thin disc rock samples are also dangerous points, which are in the pure shear stress state, and the principal stresses of the dangerous points are $\tau_{r z \max }, 0$, and $-\tau_{r z \max }$.
According to the Mohr-Coulomb Strength Theory, it is obviously obtained that shear is the main cause of the bending failure. It shows that the four kinds of discs also suffer from shear failure from the neutral points of the central cross-section, i.e., the points $e$ in Figure 13; this location is also the points of crack initiation.

In summary, the crack initiation points for the samples GS10, RS05, and RS10 are $a$ and $e$ as shown in Figure 13; the crack develops resulting from the upper point $a$ of the central cross-section which is tensed along the tangential direction and the neutral point $e$ of the central cross-section which is sheared. The crack initiation points for sample GS05 are $a, c$, and $e$ in Figure 13; they are caused by the upper points $a$ of the central cross-section and the lower points $c$ of the edge cross-section that are tensed simultaneously along the tangential direction at the center and radial direction at the edge and the neutral points $e$ of the central crosssection that is sheared. Briefly, tension-shear failure is the main reason for crack initiation.

4.3.2. The Cause of Crack Propagation. As seen in Table 4, there are two dangerous locations in sample GS05. One is at the disc center, where $\tau_{r z \max }$ and $\sigma_{\theta \max }$ play major roles, and $\tau_{r z \max }$ is about 2.06 times of $\sigma_{\theta \text { max }}$. The other is at the lower points of the disc edge, which is the uniaxial tensile stress state dominated by $\sigma_{r \text { max }}$. Crack propagation in this disc is caused by the tangential tensile stress and shear stress at the center and the radial tensile stress at the edge. The cracks are developed oppositely by the tension-shear failure at the center and tension failure at the edge, producing the petal-shaped cracks shown in Figure 14(a).

For sample RS05, the cracks propagate from the center, where $\tau_{r z \max }$ is only 1.38 times $\sigma_{\theta \max }$. Crack propagation 
TABLE 5: The details of the stress state at the dangerous points.

\begin{tabular}{lr}
\hline Stress state & Location of the dangerous points \\
\hline$a:$ the biaxial tensile stress state & The upper points of the central cross-section in samples of GS05, GS10, RS05, and RS10. \\
$b:$ the biaxial compressive stress state & The lower points of the central cross-section in samples of GS05, GS10, RS05, and RS10. \\
$c:$ the uniaxial tensile stress state & The lower points of the edge cross-section in the sample of GS05. \\
$d:$ the uniaxial compressive stress state & The upper points of the edge cross-section in the sample of GS05. \\
$e:$ the pure shear stress state & The neutral points of the central cross-section in samples of GS05, GS10, RS05, and RS10.
\end{tabular}

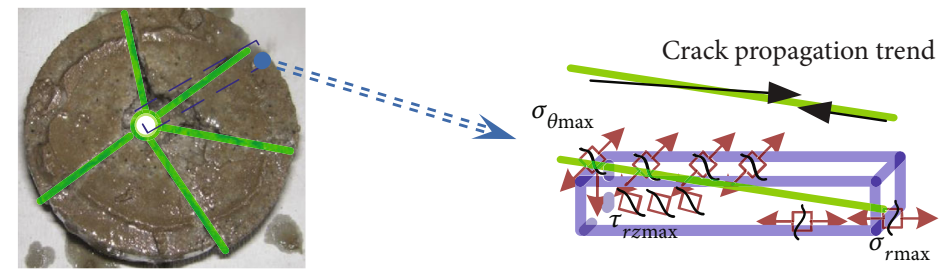

(a) GS05

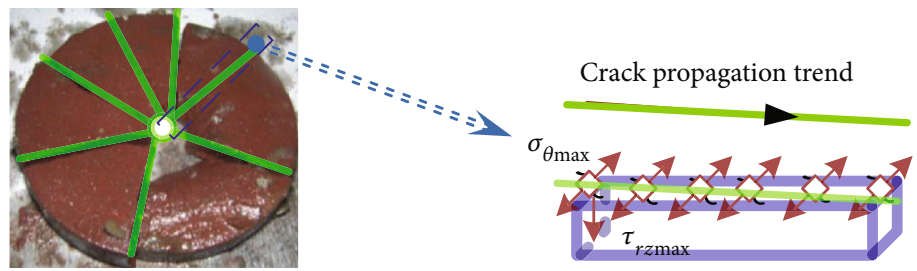

(b) RS05
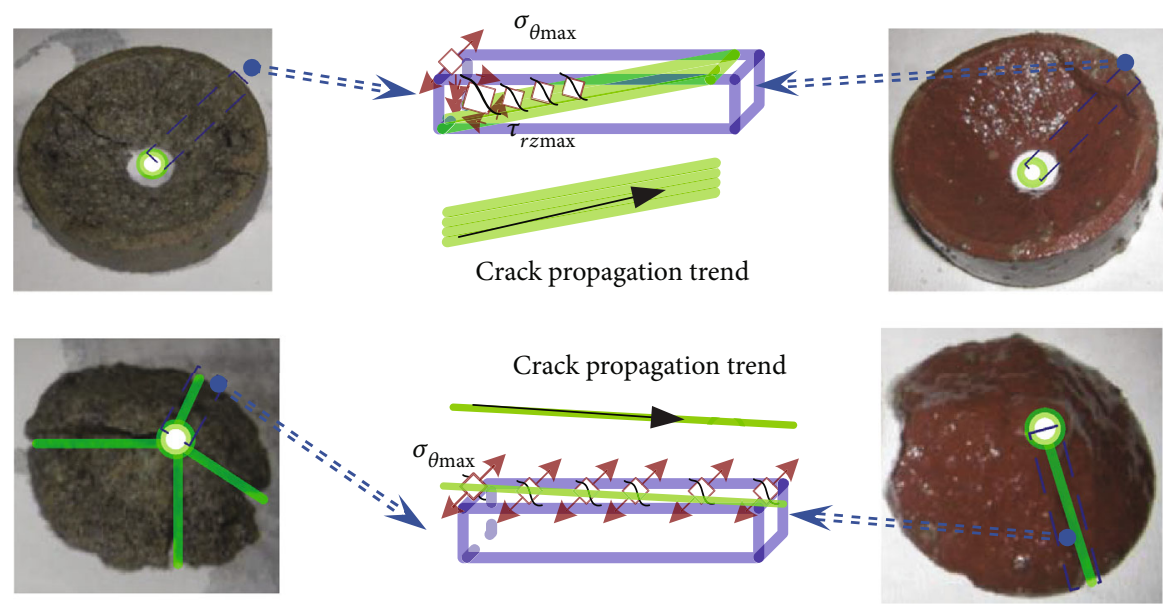

(c) GS10 and RS10

FIgURE 14: The mechanism of crack propagation.

of this disc is mainly due to the tension failure, which is perpendicular to the radius direction and caused by the tangential tensile stress. The cracks develop from the center to the edge; petal-shaped cracks are formed, as shown in Figure 14(b).

For samples GS10 and RS10, $\tau_{r z \max }$ is about 2.38 times $\sigma_{\theta \max }$. Due to the thicker thickness, crack propagation in the disc is mainly caused by shear failure; meanwhile, the tension failure plays a secondary role. As shown in Figure 14(c), the cracks rise along a conical surface with an inclination about $45^{\circ}$ from the center to the edge, and the disc rock sample is sheared into two pieces. The cap block is accompanied by petals with tension cracks caused by the tangential tensile stress.

\subsection{Bending-Failure-Induced Water Inrush Behavior in the} Floor Aquifuge. During mining activities, the floor aquifuge is bending; the deflection and stress are changing timely. It is safe when the deflection and stress are far less than the allowable values. The cracks initiate and propagate with the increase of stress, and the confined water pressure split and expand the cracks continuously. When bending failure occurs, the maximum tensile stress exceeds the allowable values; the cracks propagate to penetrate. 
Although the occurrence of bending failure is really very dangerous, the water inrush disaster does not happen immediately, because of the water inrush lagging. There is a short time to take measures to grout the cracks and to prevent the water inrush accident. According to the crack initiation and propagation (Figure 14), the grouting should be at the center or the edge of the floor aquifuge along the crack propagation trend lines.

\section{Conclusions}

A simplified thin disc model was introduced to study the bending failure of the floor aquifuge. Based on a selfdesigned experimental system, thin disc gray and red sandstone samples were tested under coupled bending-seepage condition to study the failure behavior. The failure behavior in thin disc sandstone with two different lithologies and thicknesses were analyzed. The main conclusions can be drawn as follows:

(1) The failure process of thin disc sandstone can be divided into four stages: adaptive adjustment and elastic deformation stage, plastic deformation and microcrack development stage, bearing capacity strengthening and macrocrack formation stage, and postfracture stage, of which water inrush disaster occurs at the postfracture stage.

(2) The permeability changes from $10^{-17} \mathrm{~m}^{2}$ to $10^{-11} \mathrm{~m}^{2}$ in the thin disc structure, and the sharp increase leads to more sudden and intense water inrush. The peak permeability always lags the peak load, and the lagging time of water inrush in gray sandstone is longer than that in red sandstone owing to the difference of crack propagation.

(3) The crack initiation point occurred at the center because of the tangential tensile stress and shear stress. The crack propagation is related to disc thickness and lithology.

(4) Water inrush accident occurs after the bending failure in the floor aquifuge. It is an opportune moment to grout along the crack propagation trend lines to prevent the water inrush disasters.

\section{Abbreviations}

a: $\quad$ Radius of the thin disc rock sample (L)

$A_{1}, A_{2}, A_{3}, A_{4}$ : Coefficients (-)

$C: \quad$ Cohesion $\left(\mathrm{ML}^{-1} \mathrm{~T}^{-2}\right)$

$D: \quad$ Bending stiffness of thin disc $\left(\mathrm{ML}^{2} \mathrm{~T}^{-2}\right)$

E: $\quad$ Elastic modulus $\left(\mathrm{ML}^{-1} \mathrm{~T}^{-2}\right)$

$F$ : $\quad$ Circumferential load $\left(\mathrm{MLT}^{-2}\right)$

$F_{S r}, F_{S \theta}: \quad$ Shearing internal forces $\left(\mathrm{MLT}^{-2}\right)$

$k: \quad$ Permeability $\left(\mathrm{L}^{2}\right)$

$M: \quad$ Force couple $\left(\mathrm{ML}^{2} \mathrm{~T}^{-2}\right)$

$M_{r}, M_{r \theta}, M_{\theta}: \quad$ Internal force couples $\left(\mathrm{ML}^{2} \mathrm{~T}^{-2}\right)$

$P: \quad$ Concentrated force $\left(\mathrm{MLT}^{-2}\right)$

$P_{\max }: \quad$ Peak load $\left(\mathrm{MLT}^{-2}\right)$

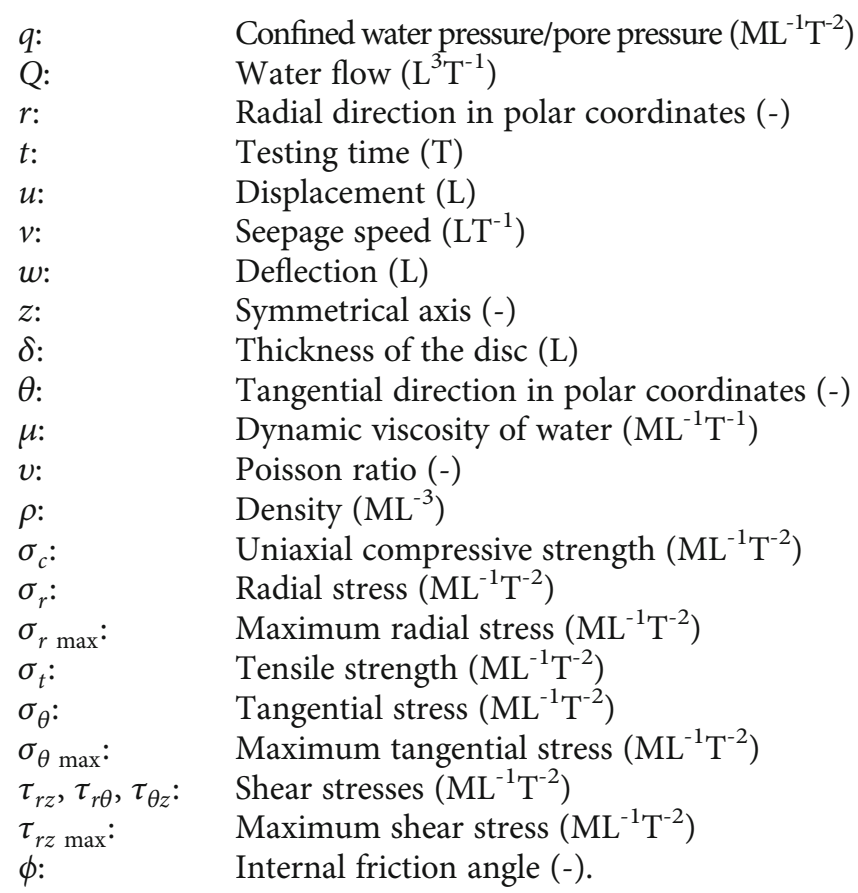

\section{Data Availability}

The data used to support the findings of this study are available from the corresponding author upon request.

\section{Conflicts of Interest}

The authors declare that they have no conflict of interest.

\section{Acknowledgments}

The authors gratefully acknowledge the support provided by the National Natural Science Fund (11502229), the Natural Science Foundation of Jiangsu Province of China (BK20160433), the Program of Yellow Sea Elite in Yancheng Institute of Technology (2019), the Program of Outstanding Young Scholars in Yancheng Institute of Technology (2014), the Program of Yellow Sea Team in Yancheng Institute of Technology (2019), and the Program of innovative training program for College Students in Yancheng Institute of Technology (2020).

\section{References}

[1] J. Wang and H. D. Park, "Coal mining above a confined aquifer," International Journal of Rock Mechanics and Mining Sciences, vol. 40, no. 4, pp. 537-551, 2003.

[2] J. Zhang and B. Shen, "Coal mining under aquifers in China: a case study," International Journal of Rock Mechanics and Mining Sciences, vol. 41, no. 4, pp. 629-639, 2004.

[3] L. Wang, Z. Chen, H. Kong, and H. Shen, "Effects of pore pressure on permeability of sandstone during bending deformation," International Journal of Rock Mechanics and Mining Sciences, vol. 70, pp. 26-32, 2014.

[4] D. Ma, J. Wang, X. Cai et al., "Effects of height/diameter ratio on failure and damage properties of granite under coupled bending and splitting deformation," Engineering Fracture Mechanics, vol. 220, article 106640, 2019. 
[5] L. Shi, Study of the Water-Inrush Mechanism and Prediction of the Water-Resisting Floor, Shandong University of Science and Technology, Taian, China, 1999.

[6] Z. Wang and H. Liu, Coal Mining above the Confined Aquifer, China Coal Industry Publishing House, Beijing, China, 1993.

[7] M. Qian, X. Miao, and J. Xu, Theory of Key Stratum in Ground Control, University of Mining and Technology Press, Xuzhou, China, 2003.

[8] J. Zhang and Y. Zhang, Seepage in Rock Fissures and WaterInrush from the Floor of the Coal Seam, Geology Press, Beijing, China, 1997.

[9] S. Peng and J. Wang, Safe Coal Mining above Confined Aquifers, Coal Industry Publishing House, Beijing, China, 2001.

[10] P. Gong, Y. Hu, Y. Zhao, and D. Yang, “Three-dimensional simulation study on law of deformation and breakage of coal floor on mining above aquifer," Chinese Journal of Rock Mechanics and Engineering, vol. 24, no. 23, pp. 4396-4402, 2005.

[11] Y. Hu, Y. Zhao, and D. Yang, "Simulation theory and method of 3D solid-liquid coupling," Journal of Liaoning Technical University, vol. 26, no. 2, pp. 204-206, 2007.

[12] Z. Li, S. Zhang, and F. Du, "Novel experimental model to investigate fluid-solid coupling in coal seam floor for water inrush," Technical Gazette, vol. 25, no. 1, pp. 216-223, 2018.

[13] J. Chen, L. Yin, W. Sun, C. Lu, S. Zhang, and X. Sun, “Development and application for new solid-fluid coupling similar material of deep floor aquifuge," Chinese Journal of Rock Mechanics and Engineering, vol. 34, Supplement 2, pp. 39563964, 2015.

[14] Q. Kang, W. Zhang, P. Han, and D. Zhang, "Experimental study of mine-induced underlying strata failure regularity in three dimensional stress condition," Chinese Journal of Underground Space and Engineering, vol. 13, no. 3, pp. 612-618, 2017.

[15] S. Liu, W. Liu, and J. Shen, "Stress evolution law and failure characteristics of mining floor rock mass above confined water," KSCE Journal of Civil Engineering, vol. 21, no. 7, pp. 2665-2672, 2017.

[16] X. Hua, M. Yang, Q. Liu, and P. Yang, "Model test on evolution mechanism of floor heave in gob-side retaining entry of deep mine," Journal of Mining and Safety Engineering, vol. 35 , no. 1, pp. 1-9, 2018.

[17] X. Miao, R. Chen, and H. Bai, "Fundamental concepts and mechanical analysis of water-resisting key strata in waterpreserved mining," Journal of China Coal Society, vol. 32, no. 6, pp. 561-564, 2007.

[18] J. Sun and L. Wang, "Instability mechanics criterion of inclined water-resisting key strata in coal seam floor," Journal of China Coal Society, vol. 39, no. 11, pp. 2276-2285, 2014.

[19] Y. Gao, S. Liu, B. Lyu, and K. Li, "Mechanism study of floor water inrush around mining field based on micro-crack extension," Journal of Mining and Safety Engineering, vol. 33, no. 4, pp. 624-629, 2016.

[20] S. Wang, K. Zhang, J. Jiang, J. Xia, and G. Zhu, "Damage and control mechanism of thick and hard floor of large chamber in deep mines," Chinese Journal of Geotechnical Engineering, vol. 38, no. 7, pp. 1316-1323, 2016.

[21] W. Guo, J. Zhao, L. Yin, and D. Kong, "Simulating research on pressure distribution of floor pore water based on fluid-solid coupling," Arabian Journal of Geosciences, vol. 10, no. 1, 2017.
[22] X. Pang, Calculation and analysis of the failure depth of the structure bottom, Shandong University of Science and Technology, Qindao, China, 2017.

[23] X. Xie, Study on floor water inrush mechanism and its application in grouting reinforcement working face under high water pressure and large mining height, China University of Mining and Technology, Beijing, China, 2018.

[24] X. Miao, Z. Chen, S. Li, and Y. Liu, "A Permeation Testing Device for Shear Rock Samples," 2011, China Patent 201110046283.X.

[25] S. Li, Study on the mechanism and control of floor heave of soft rock roadway in Gequan mine, Central South University, Changsha, China, 2004.

[26] F. Zhang, The research on space-time evolution of confined water in mining coal floor fractures, AnHui University of Science and Technology, Huainan, China, 2014.

[27] L. Shi, "The mechanical analysis of water-inrush from mining floor," Coal Geology \& Exploration, vol. 5, pp. 37-39, 1998.

[28] S. Li, K. Wang, L. Li, Z. Zhou, S. Shi, and S. Liu, "Mechanical mechanism and development trend of water-inrush disasters in karst tunnels," Chinese Journal of Theoretical and Applied Mechanics, vol. 49, no. 1, pp. 22-30, 2017.

[29] J. Heiland, "Permeability of triaxially compressed sandstone: influence of deformation and strain-rate on permeability," Pure and Applied Geophysics, vol. 160, no. 5, pp. 889-908, 2003.

[30] S. I. Mayr, H. Burkhardt, Y. Popov, and A. Wittmann, "Estimation of hydraulic permeability considering the micro morphology of rocks of the borehole YAXCOPOIL-1 (impact crater Chicxulub, Mexico)," International Journal of Earth Sciences, vol. 97, no. 2, pp. 385-399, 2008.

[31] J. E. Elkhoury, A. Niemeijer, E. E. Brodsky, and C. Marone, "Laboratory observations of permeability enhancement by fluid pressure oscillation of in situ fractured rock," Journal of Geophysical Research: Solid Earth, vol. 116, article B02311, 2011.

[32] S. Wang, D. Elsworth, and J. Liu, "Permeability evolution during progressive deformation of intact coal and implications for instability in underground coal seams," International Journal of Rock Mechanics and Mining Sciences, vol. 58, pp. 34-45, 2013.

[33] S. Wang, D. Elsworth, and J. Liu, "Mechanical behavior of methane infiltrated coal: the roles of gas desorption, stress level and loading rate," Rock Mechanics and Rock Engineering, vol. 46, no. 5, pp. 945-958, 2013.

[34] Q. Kong, H. Wang, and W. Xu, "Experimental study on permeability and porosity evolution of sandstone under cyclic loading and unloading," Chinese Journal of Geotechnical Engineering, vol. 37, no. 10, pp. 1893-1900, 2015.

[35] Z. Chao, H. Wang, W. Xu, L. Yang, and K. Zhao, "Variation of permeability and porosity of sandstones with different degrees of saturation under stresses," Chinese Journal of Rock Mechanics and Engineering, vol. 36, no. 3, pp. 665680, 2017.

[36] J. Zhang, Z. Song, W. Fan, and D. Huang, "Experimental study on mechanical behavior and permeability characteristics of sandstone under stress-seepage coupling," Chinese Journal of Rock Mechanics and Engineering, vol. 38, no. 7, pp. 13641372, 2019.

[37] C. Ding, Y. Zhang, X. Yang, D. Hu, H. Zhou, and J. Lu, "Permeability evolution of tight sandstone under high confining 
pressure and high pore pressure and its microscopic mechanism," Rock and Soil Mechanics, vol. 40, no. 9, pp. 33003308, 2019.

[38] H. Lu, X. Xiangshuai, W. Yan, and D. Yao, "Circular sliding solution for mining stability and failure depth of the layered structure of floor in coal face," Rock and Soil Mechanics, vol. 41, no. 1, pp. 1-9, 2020. 